\title{
Mulemba
}

Revista Angolana de Ciências Sociais

$4(8) \mid 2014$

Globalização, gestão e dinâmicas de desenvolvimento regional e local

\section{Abolicionismo versus colonialismo: Rupturas e continuidades em Angola (século XIX)}

Abolitionism versus colonialism: ruptures and continuities in Angola (XIX

century)

\section{Roquinaldo Ferreira}

\section{OpenEdition}

Journals

\section{Edição electrónica}

URL: https://journals.openedition.org/mulemba/245

DOI: $10.4000 /$ mulemba.245

ISSN: 2520-0305

\section{Editora}

Edições Pedago

\section{Edição impressa}

Data de publição: 1 novembro 2014

Paginação: 101-126

ISSN: 2182-6471

Refêrencia eletrónica

Roquinaldo Ferreira, «Abolicionismo versus colonialismo: Rupturas e continuidades em Angola (século $X I X) »$, Mulemba [Online], 4 (8) | 2014, posto online no dia 28 novembro 2016, consultado o 21 setembro 2021. URL: http://journals.openedition.org/mulemba/245 ; DOl: https://doi.org/10.4000/mulemba.245

Este documento foi criado de forma automática no dia 21 setembro 2021.

Tous droits réservés 


\section{Abolicionismo versus colonialismo: Rupturas e continuidades em Angola (século XIX)}

Abolitionism versus colonialism: ruptures and continuities in Angola (XIX

century)

Roquinaldo Ferreira

\section{NOTA DO EDITOR}

Recepção do manuscrito: 13/04/2014

Aceite para publicação: 20/04/2014

\section{NOTA DO AUTOR}

O presente texto integrou um conjunto de quatro conferências que o historiador brasileiro Roquinaldo Ferreira, na sua qualidade de professor visitante da FCS da UAN, orientou em Luanda nos dias 2, 4, 5 e 6 de Dezembro de 2013, sob os auspícios do Departamento de História (DH) da FCS da UAN.

\section{Introdução}

1 A relação entre o fim do tráfico de escravos e o início do colonialismo europeu na África sub-saariana tem sido objeto de intenso debate entre historiadores nas últimas décadas (HOPKINS 1973; LAW 1993: 91-115; LAW ed., 1995: 1-31). Neste debate, Seymour Drescher afirmou recentemente que o abolicionismo não teria nenhuma conexão com o 
início de relações colonialistas na África do século XIX (DRESCHER 2010: 129-150). Este ponto de vista toma como ponto de partida o caso britânico e merece ser melhor analisado no que toca ao caso português. Na primeira metade do século XIX, à medida em que o movimento para abolir o comércio transatlântico de escravos ganhou força, Portugal implementou várias políticas para revitalizar os laços coloniais com Angola. Tendo como pano de fundo a transição para o chamado comércio legítmo, tais políticas eram baseadas no fomento à agricultura comercial de large escala e levariam ao crescimento do trabalho forçado na colónia portuguesa.

O caso angolano precisa ser situado no contexto mais amplo da África atlântica, pois a transição do tráfico de escravos para o comércio legítimo foi um processo que afectou não só Angola como também outras regiões africanas. Teria o fim do tráfico trazido mudanças estruturais para as sociedades e economias africanas? Ou teria o comércio de escravos - e, por conseguinte, sua abolição e transição para o comércio legítmo - tido um impacto marginal? Na visão de David Eltis, que toma como base o conjunto da África Atlântica, as somas per capita do comércio externo em bens legais - aqui incluído o tráfico atlântico de escravos - foram muito baixas para provocar mudanças estruturais (ELTIS 1987: 229-230; AUSTEN 1970: 257-274). Segundo Jill Dias, no entanto, «a substituição gradual do comércio Atlântico de escravos pelo comércio de matérias primas e bens agrícolas teve produndas repercussões nas estruturas europeias e africanas em Angola» (DIAS 1981: 349; ver igualmente DIAS 1998: 321-378).

3 Apesar das transformações assinaladas por Dias, não existe consenso entre especialistas sobre a natureza do abolicionismo português e sua relação com o advento de novas formas de relações colonialistas. Segundo W. G. Clarence-Smith, as políticas coloniais só teriam começado na década de $1860 \mathrm{e}$, por conseguinte, não teriam relação com o abolicionismo (CLARENCE-SMITH 1985: 24-61; para visão contrária ver ALEXANDRE 2000: 127; para o caso britânico ver REYNOLDS 1974: 65; BROWN 2010: 92). João Pedro Marques afirma que as políticas anti-tráfico portuguesas foram um produto da honra $\mathrm{e}$ orgulho nacional português em relação à campanha britânica contra o comércio de escravos (MARQUES 2006). R. J. Hammond argumenta que o colonialismo português fora produto do compromisso ideológico lusitano em relação a África e não tinha racionalidade económica (HAMMOND 1996). Neste debate, a única excepção é a avaliação Gabriel Paquette, que afirma que os «debates sobre os méritos [da implantação] do colonialismo não cessaram entre 1820 e 1850, muito embora estas políticas [colonialistas] tenham sido implementadas de forma inconsistente e não sistemática, gerando poucos resultados duradouros» (PAQUETTE 2010).

\section{Projectos agrícolas: Debates e realidades}

Segundo Valentim Alexandre, mesmo antes da independência do Brasil, em 1822, Portugal já aventava a hipótese de estreitar os laços coloniais com Angola (ALEXANDRE 2004: 112). Tais laços, na visão metropolitana, seriam fortalecidos com a abolição do tráfico de escravos e a promoção da agricultura comercial em Angola. Em 1815, por exemplo, partidários da agricultura comercial já argumentavam que o comércio de escravos tolhia Angola de mão de obra e impedia o desenvolvimento económico da colónia (ALBUQUERQUE 1867: 42; BALBI 1822: 95-96). ${ }^{1}$ Este ponto de vista não ficaria restrito à metrópole e serviria de molde para políticas de fomento agrícola implementadas por autoridades coloniais em Angola. 
5 Em 1827, for exemplo, o governador de Angola Nicolau de Abreu Castelo Branco teceu uma série de considerações sobre as perspectivas da agricultura comercial na colónia. Apesar de admitir que as secas e o solo árido da região costeira de Angola constituíam sérios obstáculos para o desenvolvimento da indústria do açúcar, Castelo Branco manifestou optimismo em relação ao cultivo comercial do algodão e do índigo. De acordo com o governador, o algodão já estava sendo cultivado em Golungo e o índigo podia ser encontrado no interior angolano - sertões. Na visão de Castelo Branco, era promissor o cultivo de açúcar para a produção de cachaça, um produto amplamente consumido em Angola e que era importado do Brasil. ${ }^{2}$

6 A defesa da agricultura aumentou ao mesmo tempo em que cresceram as críticas ao comércio de escravos. Isto é demonstrado pelas reflexões de Sebastião Xavier Botelho, um ex-governador de Cabo Verde, que escreveu um livro argumentando que o fim dos embarques de cativos estimularia o comércio legítimo e serviria como uma compensação pelas perdas sofridas por Portugal com a independência do Brasil, em 1822 (BOTELHO 1840: 20). Ponto de vista semelhante foi esposado por José Joaquim Lopes de Lima, um influente publicista metropolitano, que escreveu que «o tráfico [era] tão infame como nocivo aos verdadeiros interesses das nossas possessões africanas, cuja cultura se roubavam os braços que iam fertilizar terras estranhas [Brasil]» (LIMA 1846: XXXVIII).

7 Mas entre as reflexões destes intelectuais públicos e a realidade angolana havia uma grande distância. Isto é ilustrado pela companhia de agricultura e indústria de Angola e Benguela. ${ }^{3}$ Gestado em Angola, este projecto contou com apoio metropolitano e foi implementado seis anos após a primeira tentativa de abolir as exportações de cativos, em 1830. O pressuposto era que o «fim» do tráfico (algo que, na prática, não ocorreu) criaria um quadro favorável ao desenvolvimento da agricultura angolana. Segundo os promotores da companhia de agricultura e indústria de Angola e Benguela, faria o preço de escravos subir no Brasil, encarecendo os custos de produção de bens agrícolas na excolónia portuguesa, além de reduzir os preços dos escravos em Angola - barateando a produção agrícola. ${ }^{4}$

8 Na proposta inicial, os promotores da companhia diziam que esta existiria por dez anos e seria responsável pela importação do maquinário para cultivar e processar açúcar, algodão e outros produtos. O capital viria da venda de quatrocentas cotas, cada uma valendo cem mil réis, para investidores privados. ${ }^{5} \mathrm{O}$ apoio oficial veio através da permissão do uso gratuito de terrenos públicos. No entanto, a companhia terminou em fracasso pois a maioria dos investidores eram antigos traficantes de escravos, que retomaram os investimentos no tráfico tão logo ficou claro que o decreto abolicionista de 1836 não seria cumprido. Como o governador de Angola Adrião Acácio da Silveira Pinto diria quinze anos depois deste debacle, «um grande obstáculo que se apresenta à cultivação em grande escala dos géneros coloniais é a esperança da população que devia dar exemplo de traficar na exportação de negros para além mar». ${ }^{6}$

\section{Políticas agrícolas}

9 Apesar do fracasso da companhia de agricultura e indústria de Angola e Benguela, a administração portuguesa adoptaria uma séria de políticas de promoção da agricultura comercial durante o ápice do tráfico ilegal de escravos, na década de 1840. Isto é ilustrado pelo curto mandato do governador de Angola António Manoel de Noronha, um antigo crítico do tráfico de escravos, que foi designado governador de Angola em 
1838. Durante a administração de Noronha (entre Janeiro e Outubro de 1839), o governo de Luanda se tornaria um agente activo na formulação e implementação de projectos agrícolas, criando um modelo de intervenção estatal na agricultura que balizaria iniciativas que os portugueses adoptariam no futuro.

Mesmo antes de partir para Angola, Noronha requereu ajuda do cônsul português em Pernambuco para contratar dois mestres na produção do açúcar. ${ }^{7} \mathrm{Na}$ visão do novo governador, os projectos agrícolas eram parte de um esforço maior para reforçar as ligações coloniais portuguesas com Angola, que envolviam uma série de medidas no âmbito económico e infra-estrutural, tais como a construção de uma estrada entre Luanda e Pungo Andongo e incentivos a mineração de ferro. Tal esforço tinha uma clara dimensão geo-política, pois preconizava a consolidação da soberania portuguesa em territórios então em disputa perto do rio Zaire - algo que só seria efectivado muito depois da passagem de Noronha por Luanda. ${ }^{8}$ No âmbito das fronteiras internas, envolvia a promoção de estudos científicos sobre a flora e fauna angolanas, que redundou no envio de viajantes europeus ao interior da colónia. ${ }^{9}$

Durante a administração de Noronha, o governo de Luanda participou activamente da fundação de uma colónia agrícola no presídio de Duque de Bragança, que havia sido recentemente conquistado e que era considerado ideal para a agricultura por causa da qualidade do solo e do clima. ${ }^{10}$ Para tanto, a coroa portuguesa patrocinaria o envio para Angola de mais de cem colonos de várias partes do Brasil - particularmente do Rio de Janeiro, Recife e Pará. ${ }^{11}$ Esta iniciativa guardou estreita semelhança com o projecto que levou a criação da colónia agrícola de Mossâmedes, no final da década de 1840.

o fomento à agricultura comercial foi considerado vital, com Noronha utilizando várias estratégias para atingir tal objectivo. O governador tentaria convencer Portugal a eliminar os impostos na entrada de produtos agrícolas importados de Angola. ${ }^{12}$ Persuadiria a coroa a eliminar os impostos de importação sobre equipamentos agrícolas em Angola. ${ }^{13}$ Significativamente, Noronha incentivaria a agricultura comercial entre os africanos, oferecendo isenção do trabalho como carregadores a «todos os pretos vassalos da coroa portuguesa, chamados aqui filhos dos sobas, e que até o presente não tem sido mais que escravos de particulares, a favor dos quais eram pelos chefes dos distritos obrigados a trabalhar gratuitamente.» ${ }^{14}$

13 Não há como negar, contudo, que Noronha esteve longe de obter sucesso absoluto. Por exemplo, devido à falta de capital e de pessoas qualificadas, a estrada entre Luanda e Pungo Andongo não foi construída. Outros projectos, tais como o fomento da mineração, também malograram, por conta da falta de recursos financeiros e da instabilidade política que caracterizou o curto mandato de Noronha em Luanda. Neste quadro, a prometida isenção do trabalho de carregador para os africanos que se engajassem na agricultura acabou nunca sendo implementada. ${ }^{15}$

14 No entanto, é importante frisar que estas dificuldades não significaram o fim das políticas de fomento à agricultura comercial em Angola e que estas políticas seriam implementadas mesmo depois da administração de Noronha. No governo de Pedro Alexandrino da Cunha, as autoridades de Luanda tentariam convencer um chefe africano - soba Bango Aquitamba, um grande produtor agrícola do Golungo - a iniciar o cultivo comercial do algodão, café e tabaco. ${ }^{16}$ Cunha foi o primeiro governador de Angola a enfrentar com êxito o poderoso lobby de traficantes de escravos, que dominava a política de Luanda e via a agricultura como elemento central para o soerguimento da economia angolana no pós-tráfico. Para persuadir Aquitamba a 
investir na agricultura comercial, o governo de Luanda teria até se oferecido para ajudar na comercialização em Luanda dos produtos cultivados nas terras do chefe africano. ${ }^{17}$

Igualmente significantivo foi o apoio que o governo de Luanda daria a vários projectos agrícolas de imigrantes portugueses e moradores angolanos. No primeiro caso, António de Magalhães Mesquita, um português que chegou em Luanda no início da década de 1840, recebeu autorização para estabelecer dois engenhos de açúcar em Bengo e em Cambambe. ${ }^{18}$ Ainda mais significativo foi o apoio que o governo de Luanda daria (durante a administração de Pedro Alexandrino da Cunha) aos projectos agrícolas de Ana Joaquina dos Santos Silva, uma das maiores traficantes de escravos de Angola, cujo interesse na agricultural comercial (sobretudo cultivo e refino de açúcar) foi tão intenso, que ela teria até mesmo visitado fazendas açúcareiras no Brasil: «ela esteve no Brasil e testemunhou o processo de cultivo e processamento do açúcar». ${ }^{19}$

Os investimentos de Santos Silva merecem ser devidamente situados no contexto mais geral do fim do tráfico de escravos. Antes desta investidora, outros angolanos já haviam se aventurado no cultivo e produção de açúcar. Na década de 1830, por exemplo, engenhos - provavelmente para a produção do rum - já haviam sido instalados perto do rio Bengo. ${ }^{20}$ Posteriormente, o governo de Luanda afirmaria que «há nesta cidade um morador que ali tem arrimos e gados e que tem tentado assentar um engenho de açúcar, para o que tem a maior parte das pessoas necessárias. ${ }^{21}$

No entanto, é inegável que Santos Silva foi o mais importante nome da fase inicial da produção açucareira em Angola. Apesar das perdas iniciais, seus investimentos serviriam como modelo no pós-tráfico. ${ }^{22}$ Segundo um diplomata britânico, "a única tentativa de conferir uma nova direcção para a economia [...] está sendo feita agora por Dona Ana Santos Silva, que tinha sido ela própria uma escrava e cujo nome tem frequentemente figurado nos relatórios sobre o tráfico como sendo uma pessoa intimamente envolvida» com o comércio de escravos. ${ }^{23}$ Segundo José Carlos Caldeira, Santos Silva tinha, em 1851, obtido «excelentes amostras de açucar e aguardente» (CALDEIRA 1853: 211). Nas várias fazendas da ex-traficante, 1.500 cativos trabalhavam em várias produções agrícolas, incluindo plantações de açúcar. ${ }^{24}$

Estas fazendas eram estrategicamente situados no Bengo, relativamente próximas de Luanda, onde vários relatos demonstram a existência de grande demanda pela cana de açúcar produzida locamente. No final da década de quarenta, dizia-se que «a cana de açucar produz com abundância nas margens dos rios, e mesmo nas terras do interior: os negros trazem diariamente em canoas do Bengo, Dande e etc, para o mercado da Quitanda chamada do Peixe para mais de trinta mil canas, que ali se vendem a razão de duas por 25 réis, que o povo preto compra para mastigar. Toda a cana e de boa qualidade e muito suculenta.» ${ }^{25}$ Posteriormente, um viajante português relataria que «nas margens do Bengo e Dande produz-se muita cana de açucar de boa qualidade e dali trazem os negros diariamente grande número de canas para o mercado da Quitanda em Loanda, e que o povo preto compra para mastigar» (CALDEIRA 1853: 211).

Embora seja evidente que nem toda cana de açúcar consumida em Luanda vinha das fazendas de Santos Silva, é evidente que os investimentos desta empresária se inseriam nas políticas coloniais de fomento da agricultura comercial. Tais políticas eram baseadas na instalação de engenhos de açúcar perto de Luanda, de forma a facilitar o transporte do açúcar para a cidade e posterior exportação. ${ }^{26}$ Com efeito, o interesse oficial nos investimentos de Santos Silva foi tal, que o governador de Angola Adrião 
Acácio da Silveira Pinto chegou a visitar uma das propriedades da ex-traficante, em $1851 .{ }^{27}$ Numa tentativa de repetir o sucesso de Santos Silva, o governo de Luanda enviaria sementes recolhidas das fazendas da empresária para várias partes de Angola - incluindo a recém-criada colônia agrícola Mossâmedes, no sul de Angola. ${ }^{28}$

Igualmente importante foi o facto que as políticas de fomento e a agricultura comercial não se circunscreveram aos investimentos no cultivo e produção de açúcar e que os portugueses também patrocinaram o cultivo comercial de outros produtos. Em 1845, por exemplo, os administradores do monopólio do tabaco, em Lisboa, se comprometeriam a comprar um máximo de oito mil arrobas de tabaco angolano por ano. ${ }^{29} \mathrm{~A}$ decisão foi uma vitória para o governo de Luanda, que havia enviado amostras do produto para Lisboa. Em 1855, autoridades metropolitanas instruiriam os donos de contratos de tabaco a comprar quinhentas arrobas de tabaco angolano..$^{30}$

$\mathrm{O}$ apoio metropolitano ao cultivo comercial de tabaco se estenderia à divulgação de técnicas agrícolas (através da tradução e publicação de manuais), assim como à distribuição de sementes de tabaco norte americano - na altura em grande demanda no mercado internacional (FERREIRA 1877: 42; WELWITSCH 1962 [1861]: 31-39). O governo financiaria as viagens do cientista austríaco Friedrich Welwitsch, que foi contratado por Lisboa para estudar a fauna e flora de Angola em 1854. Segundo Welwitsch, as políticas de fomento do cultivo do tabaco teriam tido «resultados tão satisfatórios que actualmente tanto a plantação de tabaco da Virginia como a de algodão da Louisianne já se acham assaz generalizadas nestes distritos montanhosos e muitas plantaçõeses deste ano já são feitas com as sementes alcançadas neste pais» (WELWITSCH 1867: 293-294).

Além do tabaco e açúcar, as políticas de fomento a agricultura tiveram como objectivo o cultivo comercial do algodão, cuja variedade silvestre já crescia em várias partes de Angola. Em 1839, por exemplo, o ex-governador de Angola António de Saldanha Gama assinalaria que as redes de pesca usadas por Muxiloandas (moradores da ilha de Luanda) eram manufacturadas com algodão local, assim como tecidos fabricados por africanos do interior (GAMA 1839: 73-74). Posteriormente, Welwitsch afirmaria que «não haver em toda a província de Angola um único distrito em que os indígenas deixassem de cultivar maior ou menor porção de algodão, ora somente para uso doméstico, ora também para comércio» (WELWITSCH 1962 [1861]: 31-39). Dizia-se que o algodão «dá-se por toda a parte e com abundância», sendo tão bom quanto o melhor algodão brasileiro. ${ }^{31}$

o fomento ao cultivo de algodão se iniciaria de forma sistemática na década de 1840 . Em 1845, por exemplo, o cônsul português em New York recebeu ordens de Lisboa para adquirir duas máquinas de descaraçoar algodão, que seriam posteriormente enviadas a Angola. ${ }^{32}$ Mais tarde, duas máquinas para limpar algodão foram enviadas para Mossâmedes, onde a produção algodoeira chegou a cinquenta arrobas em 1855 (CASTRO 1867: 134-135). ${ }^{33}$ Como no caso da produção de tabaco, a estratégia de Luanda tinha como objectivo promover a produção do algodão entre os africanos. Para tanto, Welwitsch recebeu instruções para distribuir sementes de algodão vindas dos Estados Unidos em Ambaca, em Golungo Alto e em Cazengo (WELWITSCH 1962 [1861]: 31-39). Para incentivar a recolha e cultivo do algodão entre os africanos, o governo de Luanda começou a aceitar o algodão como pagamento dos impostos devidos à administração (FREUDENTHAL 2005: 111). 


\section{A força do mercado interno}

Em interior e Luanda: «o total [de Outubro de 1859 a Fevereiro de 1860] foi trazido por negros livres que carregam esse montante na forma de semente, [percorrendo] uma distância considerável, às vezes, quase 100 milhas no interior.» ${ }^{36} \mathrm{O}$ quadro não seria muito diferente em relação às exportações de tabaco, que atingiriam apenas 118 arrobas em 1850 (MENEZES 1867: 18). Como explicar tal situação? Assim como o algodão, as baixas exportações de tabaco eram consequência directa do consumo interno angolano, algo que, de certa forma, é evidenciada pela existência de fábricas de charutos no Golungo e Cazengo. No Golungo, charutos manufaturados com o tabaco local eram considerados como «bons, fortes, gostosos, mas mal feitos e de folhas escuras». No Cazengo, eram descritos como «bem feitos, gostosos, de bom tabaco, porém fortíssimos» (FERREIRA 1877: 13) Como evidência da demanda interna por tabaco, serve também o facto que Angola se tornaria importadora do produto, em fins da década de 1850 (CASTRO 1862: 324).

No caso do açúcar, a situação era igualmente desapontadora. Em meados da década de 1850, o número de engenhos não passava de seis, a maior parte em Mossâmedes, uma colónia agrícola do sul de Angola, que havia sido formada por colonos portugueses fugidos de Pernambuco por conta do anti-lusitanismo no Brasil do século dezanove. Ao invés de exportar, Angola importava açúcar (MENEZES 1867: 18). Tal situação se explica por duas razões. Em primeiro lugar, a produção de açúcar exigia alto investimento, o que afastava potenciais investidores. Com efeito, é provável que o falecimento de Ana Joaquina dos Santos Silva, em 1859, tenha eliminado um dos poucos investidores que detinham suficientes cabedais para investir na cultura e produção de açúcar. Em segundo lugar, a decadência da incipiente indústria açucareira reflectia a excessiva ênfase em Mossâmedes. Depois de gastar volumosos recursos para auxiliar a instação de colonos em Mossâmedes, a administração portuguesa assistiu impotente o declínio da colónia em meio a forte resistência africana. ${ }^{37}$ 


\section{Cafeicultura: Um caso de sucesso}

28 Neste quadro, o café foi o produto agrícola que obteve mais sucesso no contexto das políticas de fomento à agricultura implementadas pelos portugueses. Mesmo antes do fim do comércio de escravos, o produto já era colhido em várias partes de Angola sobretudo a variedade silvestre. Em 1823, vendia-se em Luanda café do Encoje, região situada ao norte de Angola. O interesse pelo cultivo comercial se manifestou já na década de 1820. Durante a administração do governador Nicolau de Abreu Castelo Branco, pelo menos mil sementes de café foram plantadas em Pungo Andongo, o ponto mais distante ao leste da colônia..$^{38} \mathrm{O}$ cultivo do produto seria promovido em outras regiões - dentre as quais o Golungo e o Cazengo. ${ }^{39}$

É claro que tal interesse tinha como pano de fundo o aumento do preço do café no mercado mundial. ${ }^{40} \mathrm{Com}$ efeito, as exportações começariam em 1830, consistindo sobretudo de café silvestre (FREUDENTHAL 2005: 111; DIAS 1998: 374). Em Golungo, «o café vinha das terras de soba Cabanga Cavalunga e havia muito tempo que tinha sido "descoberto", assim como de Massangano e Dembos.» ${ }^{41} \mathrm{Em}$ 1850, o governador de Angola Adrião Acácio da Silveira Pinto escreveria que «há poucos meses foi descoberta uma grande mata de café no distrito dos Dembos, eu recomendei ao respectivo chefe que encarregasse alguém de sua confiança da sua cultura e lavra.» $\mathbf{4}^{42}$ No anos quarenta, se tornaria rotineira a venda de café silvestre em Luanda (FERREIRA 1877: 6).

A região onde a produção cafeeira alcançaria maior êxito foi o Cazengo. Já em 1830, um relatório oficial constataria a existência de quantidade significativa de café silvestre em territórios controlados por líderes africanos. ${ }^{43} \mathrm{Em} \mathrm{1838}$, o número de pés de café foi estimado em sessenta mil, com as autoridades portugueses assinalando que o Brasil poderia servir de fonte de investimentos e mão de obra para a nascente cafeicultura angolana: «seria muito vantajoso que do Brasil venhão não só operários para o fabrico dos diferentes géneros que ali se lavram mas ainda de capitalistas que em Angola possam fazer melhor fortuna». ${ }^{44}$

De facto, a participação brasileira seria uma das características centrais da produção cafeeira no Cazengo, sendo protagonizada por um brasileiro chamado João Guilherme Barboza, que foi condecorado com o título de cavalheiro da ordem de Nossa Senhora da Conceição de Viçosa, em 1845, depois de plantar sessenta mil pés de café na região. ${ }^{45}$ Muito por conta dos investimentos de Barboza, a produção de café do Cazengo alcançaria 170 sacas, em $1840 .{ }^{46} \mathrm{Em} \mathrm{1846}$, a produção atingiu 345 arrobas, levando o governador de Angola, Pedro Alexandrino da Cunha, a afirmar que a produção e exportação do café «vai aumentando muito». ${ }^{47}$ Entre 1842 e 1844 , as exportações cresceriam de 200 para 380 arrobas de café - quase tudo produzido no Cazengo (BIRMINGHAM 1978; LIMA 1846: 76-77). ${ }^{48}$ Em 1850, o café angolano foi exportado para Hamburgo. ${ }^{49}$

Em 1852, 2000 arrobas de café seriam transportadas para Luanda provenientes de várias regiões do interior - principalmente do Cazengo. ${ }^{50}$ Apesar do investimento inicial de Barboza, o café desta região não era cultivado «de acordo com o sistema em prática no Brasil». Resultava, na verdade, da recolha de café silvestre ou da colheita de café produzido a partir de técnicas agrícolas africanas (FRANCINA 1867: 452-464). Como o próprio Barboza admitiria, «o café silvestre está em todo o lugar e, em alguns lugares, é tão abundante que basta apenas pegá-lo e limpá-lo» (BARBOZA 1867: 472). Dizia-se que algumas 
árvores de café cresciam até vinte pés, em condições particularmente favoráveis devido a topografia montanhosa de Cazengo (WELWITSCH 1862: 9).

O governo de Luanda participou activamente dos esforços para impulsionar a produção cafeeira. Numa tentativa de ampliar o cultivo do produto, autoridades ordenariam o envio de sementes de café do Cazengo para outras partes de Angola. ${ }^{51}$ Atenção especial foi dada ao escoamento do produto para a costa, com o governo ordenando a construção de uma estrada do Cazengo para o rio Lucala. ${ }^{52}$ Ainda mais significativo foram as várias tentativas de melhorar o sistema de transporte do café para Luanda através do uso de camelos, que eram importados em Angola com auxílio do governo de Luanda. Em 1846, as autoridades afirmariam que a importação de camelos havia sido requisitada pelos agricultores do Cazengo, «visto que ali [Cazengo] não vingava nem o gado vacuum nem o asinino para fazer os transportes» do café para a costa. ${ }^{53}$

O êxito foi inegável. Em 1846, Barboza, o investidor brasileiro, estimou em setenta mil o número de pés de café, acrescentando que vinte mil mudas estavam sendo preparadas para o cultivo. ${ }^{54}$ Mais tarde, o número de pés de café alcançaria quinhentos mil (DIAS 1985-1986: 300). Apesar do café silvestre, é inegável que boa parte do produto era fruto do cultivo comercial. Com efeito, o número de cafeicultores foi estimado em 35 , em 1854, e estes seriam responsáveis pela produção de 1263 arrobas de café. Em 1856, certamente incluindo os cafeicultores africanos, o número de produtores foi estimado em 321, que seriam responsáveis pela produção de 1865 arrobas. Entre 1858 e 1859, as exportações alcançariam 15.032 arrobas (MENEZES 1867: 17).

\section{Qual mão de obra?}

Qual mão de obra foi utilizada nos projectos agrícolas e comerciais na África atlântica durante e após a abolição do tráfico de escravos? Paul Lovejoy argumenta que a mão de obra escrava esteve na base das relações de produção no pós-tráfico, em parte por conta da queda dos preços dos cativos em virtude do fim das exportações de escravos (LOVEJOY 1983: 135-158; MANNING 1982: 49; GORDON 2009: 926). Robin Law, por outro lado, relaciona a queda dos preços dos escravos a factores não directamente ligados ao fim do comércio internacional de escravos, além de acrescentar que generalizações sobre o crescimento da escravidão tendem a obscurecer a variedade das formas das relações sociais de produção no pós-tráfico de escravos (LAW 1995: 8; LAW 1993: 109). Segundo Ray Kea, na Costa da Ouro, a transição para a agricultura comercial se pautou pela utilização de várias formas de relações de trabalho - até mesmo o trabalho livre (KEA 1995: 120).

36 No caso angolano, a questão do trabalho foi intensamente debatida por administradores coloniais e publicistas portugueses - alguns dos quais tinham tido passagem pela máquina administrativa imperial. Segundo o governador Sebastião Lopes de Calheiros e Menezes, o «trabalho livre dos pretos, prestado aos brancos pela remuneração, que o produto da agricultura dos trópicos permite dar, é um sonho, ao menos por ora» (MENEZES 1867: 67). Ao indirectamente defender o uso da mão de obra escrava, Menezes tomava partido num debate que havia começado duas décadas antes. Em 1840, por exemplo, Sebastião Xavier Botelho, que havia ocupado o posto de governador do Cabo Verde, escreveu um texto no qual defendia que, além da imigração e do comércio livre, a nova política colonial em relação a Angola deveria ser baseada no fim gradual da escravidão e na implantação do trabalho livre (BOTELHO 1840: 20). 
37 Na visão de autoridades coloniais e cientistas, o trabalho livre seria uma solução para a organização do trabalho agrícola em Angola, onde o grosso das tarefas agrícolas recaía sobre as mulheres, não sobre os homens. Esta divisão de trabalho africana foi capturada num relato de Welwitsch. Segundo o cientista austríaco, «o costume geral que reina entre a população preta do sexo masculino não se ocupar com a agricultura, entregando-a a execução de quaisquer trabalho agrícola, domésticos ou rurais, aos cuidados pouco acertados das suas (muitas vezes numerosas) mulheres $e$ criancas.... ${ }^{55} \mathrm{~A}$ mesma constatação foi feita por autoridades coloniais portuguesas: os homens «eram mais dificeis de domar e acostumar aos trabalhos da cultura. $\aleph^{56}$ Neste contexto, a expectativa era que o estabelecimento do trabalho livre assalariado levaria a uma maior participação masculina no trabalho agrícola. ${ }^{57}$

Do ponto de vista prático, o trabalho escravo tinha facetas negativas, tais como as constantes fugas de cativos - que era facilitada pelo facto que os escravos muitas vezes conheciam o terreno melhor que os seus donos - e seus consequentes impactos negativos sobre a produção agrícola. Tais fugas teriam levado ao abandono de vários arimos em Quifandongo, em $1841 .^{58}$ Segundo o governador de Angola Menezes, significavam que a agricultura comercial «nunca será tão produtiva como em São Tomé, Havana, Brasil ou nos Estados Unidos, pela facilidade que têm os pretos de subtrair-se à acção dos brancos, fugindo para onde não é possível buscá-los, o que não sucede nos países citados» (MENEZES 1867: 67) ${ }^{59}$ Tal situação levaria um grupo de potencial investidores a propôr a importação de escravos de Moçambique, sob alegação que os escravos angolanos fugiam facilmente e eram, portanto, impróprios para o trabalho agrícola. ${ }^{60}$

De certa forma, a prevalência do trabalho escravo resultou da queda nos preços de cativos advinda do fim do tráfico de escravos, como assinalado pelos representantes diplomáticos britânicos Edmond Gabriel e George Jackson, em 1847: «o baixo preço com o qual um negro jovem e saudável pode agora ser comprado nessa província, quase metade do que deveria ser dado por ele há dois ou três anos, embora, por um lado, possa parecer calculado para encorajar o tráfico, por outro lado, confirma os grandes dificuldades e riscos derivados dessa prática.» ${ }^{61} \mathrm{~A}$ queda nos preços de escravos é corroborada por relatos de viajantes europeus. Segundo David Livingstone, o preço de um escravo jovem teria caído de 70-80 dólares para 10-20 dólares, no início dos anos cinquenta (LIVINGSTONE 1959, I: 252-253). Na opinão de Welwitsch, este variaria entre $25 \$ 000$ e $45 \$ 000$ réis, dependendo da idade e das habilidades agrícolas (WELWITSCH 1962 [1861]: 31-39). No interior de Angola, segundo o viajante húngaro Ladislau Magyar, o fim do tráfico teria levado a uma queda em torno de 2/3 nos preços de escravos (MAGYAR no prelo: 14-17).

No entanto, é importante assinalar que o fomento a agricultura comercial também contribuiu para o crescimento da escravidão. Autoridades britânicas sustentariam que «a existência da escravidão nesta província e, especialmente, o uso de escravos por todos os agricultores no interior põe em dúvida se alguma grande plantation pode ser implementada sem recorrer ao trabalho escravo. ${ }^{62}$ Com efeito, estimativas davam conta que cada escravo seria capaz de cultivar e processar dez arrobas de algodão. ${ }^{63} \mathrm{Na}$ colónia agrícola de Mossâmedes, segundo Bernardino Freire de Figueiredo Abreu e Castro, «alguns colonos já têm comprado escravos com o produto da agricultura» (CASTRO 1867: 132-134). ${ }^{64}$

41 Mas seria incorrecto supôr que a escravidão foi a única forma de relação de produção em Angola. Assim como na bahia do Benin e Costa da Ouro, outras formas de trabalho forçado existiram no pós-tráfico angolano, principalmente o trabalho de africanos liberados de navios negreiros apreendidos pelos ingleses e portugueses - os chamados 
libertos. Ironicamente, este processo esteve intimamente associado ao avanço do abolicionismo atlântico, que tinha como objectivo o fim do tráfico de escravos mas acabaria por levar a criação de formas de trabalho forçado na África. No caso angolano, os libertos teriam que trabalhar por sete anos, numa situação não muito diferente dos escravos, antes de obterem liberdade.

O caso angolano teria, assim, claros paralelos com outras regiões africanas. Em Lagos, segundo Kristin Mann, apesar da suposta inspiração abolicionista dos britânicos, já estabelecidos como poder colonial em Lagos, as políticas abolicionistas teriam tido «efeito mínimo nas relações entre escravos e donos» (MANN 1995: 165; 2007: 160-200). Em Angola, mesmo depois do suposto decreto «abolicionista» de 1854, pouco mudou nas relações de trabalho. Além de legalizar o direito a manumissão para os escravos, o decreto de 1854 instituiu um registro de escravos, estabelecendo que cativos não registados num prazo de trinta dias seriam considerados como libertos, os quais obteriam liberdade depois de dez anos de trabalho. ${ }^{65}$ Do ponto de vista prático, contudo, as mudanças foram reduzidas.

Em primeiro lugar, a oposição ao decreto régio não tardou a se manisfestar. Em 1856, dizia-se que «o que há a fazer é tolerar o serviço dos escravos, considerando-o como se fosse livre, fazendo-o assim tornar efectivo [enquanto livre] quando a ingerência das autoridades seja pedida pelos interessados. ${ }^{66} \mathrm{~A}$ distinção entre escravos e libertos, prevista no decreto de 1854, não exitia na prática. Em 1861, o governador de Angola Menezes sustentou que «a escravidão acha-se abolida por lei, e não é de crer que reviva, porém a lei admite a condição de liberto» (MENEZES 1867: 82). Igualmente importante, o malogro do decreto de 1854 teve relação com o avanço da agricultura comercial. Como afirmou o viajante lusobritânico Joachim John Monteiro, «existem, actualmente, em Angola, várias plantações de açúcar e de algodão onde trabalham escravos, chamados, agora, de "libertos"》 (MONTEIRO 1875: 75-76).

\section{Conclusão}

44 A consequência mais importante das políticas de fomento agrícola portuguesas talvez tenha sido a expansão do consumo interno, não o avanço das exportações agrícolas. A única excepção seria o café, devido aos métodos híbridos (investimento brasileiro e técnicas de produção africanas) no Cazengo, e a forte demanda internacional. Outra excepção seria o algodão - sobretudo no perído da guerra civil americana. Seria incorrecto afirmar, contudo, que a pequena participação de bens agrícolas nas exportações ilustraria uma passividade metropolitana em relação a economia angolana no pós-tráfico. Na verdade, o fomento agrícola, assim como a redefinição de relações de trabalho, se inseriam numa série de políticas que refundaram as relações entre metrópole e colónia. Neste sentido, o aumento do trabalho forçado, não só através da manutenção da escravidão mas também através de categorias «intermediárias» como os libertos, seria condição sine qua non para a implantação de relações coloniais de exploração económica na segunda metade do século XIX. 


\section{BIBLIOGRAFIA}

ABOLIÇÃO, 1997, A abolição do tráfico e da escravatura em Angola: Documentos. Luanda, Ministério da Cultura.

ALBUQUERQUE Diogo Vieira de Tomar e, 1867, «Observações sobre alguns importantes objectos ao Estado da India Portugueza on August 31, 1815», in Annaes do Conselho Ultramarino (parte não official), Fevereiro de 1854 a Dezembro de 1858. Lisboa, Imprensa Nacional.

ALEXANDRE Valentim, 2000, Velho Brasil, novas Áfricas: Portugal e o império (1808-1975). Lisboa, Edições Afrontamento.

ALEXANDRE Valentim, 2004, «The Portuguese Empire, 1825-1890: Ideology and economies», in Olivier Pétré-Grenouilleau (ed.), From slave trade to empire: Europe and the Colonization of Black Africa, 1780s-1880. Londres e New York, Routledge, pp. 110-132.

ALMANAK, 1851, Almanak Statistico da Província d'Angola e suas Dependências para o ano de 1852. Luanda, Imprensa do Governo.

AUSTEN Ralph, 1970, «The abolition of the Overseas Slave Trade: A distorted theme in West African History", Journal of the Historical Society of Nigeria, vol. 5, n. 2, pp. 257-274.

AUSTEN Ralph e DERRICK Jonathan, 1999, Middlemen of the Cameroons rivers: The Duala and their hinterland. New York, Cambridge University Press.

BALBI Adrien, 1822, «Variétés politico-statistiques sur la Monarchie Portugaise», in Annaes das Sciencias, das Artes, e das Letras (Paris), Tomo XVI, A. Bobée.

BARBOZA João Guilherme, 1867, «Descripção do Cazengo» em 20 de junho de 1847, Annaes do Conselho Ultramarino (Parte não official), Fevereiro de 1854 a Dezembro de 1858. Lisboa, Imprensa Nacional.

BIRMINGHAM David, 1978, «The coffee barons of Cazengo», Journal of African History, vol. XIX, n.ำ 4, pp. 523-538.

BOTELHO Sebastião Xavier, 1840, Escravatura: Benefícios que podem provir às nossas possessões d'África da proibição daquele tráfico. Lisboa, Typographia de José B. Morando.

BROWN Christopher Leslie, 2010, «Empire without America: British plans for Africa in the era of the American Revolution», in Derek R. Peterson (ed.), Abolitionism and imperialism in Britain, Africa, and the Atlantic. Athens, Ohio University Press, pp. 84-100.

CALDEIRA José Carlos, 1853, Apontamentos d'uma viagem de Lisboa à China. Lisboa, Typographia de Castro \& Irmão.

CASTRO Bernardino Freire de Figueiredo Abreu e, 1862, «Breve notícia do estado da agricultura nas nossas províncias ultramarinas», in Archivo Rural: Jornal de Agricultura, Artes e Sciencias Correlativas, vol. IV.

CASTRO Bernardino Freire de Figueiredo Abreu e, 1867, «Relatório sobre Mossamedes» em 5 de Julho de 1854, Annaes do Conselho Ultramarino (parte não official), Fevereiro de 1854 a Dezembro de 1858. Lisboa, Imprensa Nacional.

CASTRO Bernardino Freire de Figueiredo Abreu e, 1867, «Relatório sobre Mossâmedes» em 27 de Agosto de 1854, in Annaes do Conselho Ultramarino (parte não official), Fevereiro de 1854 a Dezembro de 1858. Lisboa, Imprensa Nacional. 
CLARENCE-SMITH W. G., 1985, The Third Portuguese Empire. Manchester, Manchester University Press.

DIAS Jill, 1998, «Angola», in Valentim Alexandre \& Jill Dias (eds.), Nova história da expansão portuguesa: 0 império africano. Lisboa, Editorial Estampa, vol. X, pp. 321-378.

DIAS Jill, 1985-1986, «Changing patterns of power in the Luanda hinterland. The impact of trade and colonisation on the Mbundu ca. 1845-1920», Paideuma: Mitteilungen zur Kulturkunde, n. 32, pp. 285-318.

DIAS Jill, 1981, «Famine and disease in the History of Angola, c. 1830-1930», Journal of African History, vol. 22, n. 3, pp. 349-378.

DRESCHER Seymour, 2010, «Emperors of the world: British abolitionism and imperialism», in Derek Peterson (ed.), Abolitionism and imperialism in Britain, Africa, and the Atlantic. Athens, Ohio University Press, pp. 129-149.

ELTIS David, 1987, Economic growth and the ending of the Transatlantic Slave Trade. New York, Oxford University Press.

FIGUEIREDO Luiz Antonio de, 1864, Indice do Boletim Official da Provincia d'Angola (1845-1862). Lisboa, Imprensa do Governo.

FERREIRA Francisco de Salles, 1877, Do tabaco em Angola. Lisboa, Typographia Luso-Hespanhola.

FRANCINA Manuel Alves de Castro, 1867, «Viagem a Cazengo pelo Quanza e regresso por terra» em 6 de Fevereiro de 1847, in Annaes do Conselho Ultramarino (parte não official), Fevereiro de 1854 a Dezembro de 1858. Lisboa, Imprensa Nacional, pp. 452-464.

FREUDENTHAL Aida, 2005, Arimos e fazendas: A transição agrária em Angola, 1850-1880. Luanda, Edições Chá de Caxinde.

GAMA Antonio de Saldanha, 1839, Memória sobre as colônias de Portugal situadas na costa occidental d'África. Paris, Typographia de Casimir.

GORDON David, 2009, «The abolition of the slave trade and the transformation of the SouthCentral African Interior during the nineteenth century», William and Mary Quarterly, vol. LXVI, n.․․ 4, Outubro, pp. 915-938.

HAMMOND R. J., 1966, Portugal and Africa 1815-1910: A study in uneconomic imperialism. Stanford, Stanford University Press.

HOPKINS A. G., 1973, An economic history of West Africa. London, Longman.

HOPKINS Daniel P., 2009, «Peter Thonning, the Guinea Commission, and Denmark's postabolition African Colonial Policy, 1803-1850, William and Mary Quarterly, vol. LXVI, n.. 4 .

KEA Ray, 1995, «Plantations and labour in the South-East Gold Coast from the late eighteenth to the mid nineteenth century", in Robin Law (ed.), From slave trade to legitimate commerce: The commercial transition in nineteenth-century West Africa. Cambridge, Cambridge University Press.

LATHAM A. J. H., 1973, Old Calabar, 1600-1891: The impact of the international economy upon a traditional society. Oxford, Clarendon Press.

LAW Robin, 1993, «The historiography of the commercial transition in nineteenthcentury West Africa», in Toyin Falola (ed.), African historiography: Essays in honour of Jacob Ade Ajayi. Harlow, Longman, pp. 91-115

LAW Robin (ed.), 1995, From slave trade to "legitimate" commerce: The commercial transition in nineteenth-century West Africa. Cambridge, Cambridge University Press [«African Studies»; 68]. 
LIMA José Joaquim Lopes de, 1846, Ensaios sobre a statistica das possessões portuguezas na Africa Occidental e Oriental; na Asia Occidental; na China e na Oceania. Lisboa, Imprensa Nacional.

LIVINGSTONE David, 1959, Family Letters, 1841-1856. Londres, Chatto \& Windus, vol. I.

LOVEJOY Paul, 1983, Transformations in slavery: A history of slavery in Africa. New York, Cambridge University Press.

LOVEJOY Paul e RICHARDSON David, 1995, «British abolition and its impacts on slave prices along the Atlantic Coast of Africa», The Journal of Economic History, vol. 55, n.. 1, pp. 98-119.

MAGYAR Ladislau, [no prelo] Viagens no interior da África Austral nos anos de 1849 a 1857, Luanda, Arquivo Nacional de Angola.

MANN Kristin, 1995, «Owners, slaves and the struggle for labour in the commercial transition at Lagos», in Robin Law, From slave trade to "legitimate" commerce: The commercial transition in nineteenth-century West Africa. Cambridge, Cambridge University Press, pp. 144-171.

MANN Kristin, 2007, Slavery and birth of an african city: Lagos, 1760-1900. Bloomington, Indian University Press.

MANNING Patrick, 1982, Slavery, colonialism and economic growth in Dahomey, 1640-1960. New York, Cambridge University Press.

MARQUES João Pedro, 2006, The sounds of silence: Nineteenth-Century Portugal and the Abolition of the Slave Trade. New York, Berghahn Books.

MENEZES Sebastião Lopes de Calheiros e, 1867, Relatório do Governo Geral da Província de Angola para o ano de 1861, Lisboa, Imprensa Nacional.

MESEUM William, 1867, «Notícia de uma exploração da Costa Occidental da África ao Sul de Benguela» em 1855, in Annaes do Conselho Ultramarino (parte não official), Fevereiro de 1854 a Dezembro de 1858. Lisboa, Imprensa Nacional, pp. 253-257.

MONTEIRO Joachim John, 1875, Angola and the River Congo. Londres, MacMillan \& Co.

PAQUETTE Gabriel, 2010, «After Brazil: Portuguese debates on Empire, c. 1820-1850», Journal of Colonialism and Colonial History, vol. 11, n.. 2 .

PÉTRÉ-GRENOUILLEAU Olivier (ed.), 2004, From Slave Trade to Empire: Europe and the Colonization of Black Africa, 1780s-1880. New York.

REYNOLDS Edward, 1974, Trade and economic changes on the Gold Coast, 1807-1814. New York, Longman.

VALDEZ Francisco, 1864, Africa Occidental: Noticias e considerações. Lisboa, Imprensa Nacional.

WELWITSCH Friederich, 1862, Synopse explicativa das amostras de madeiras e drogas medicinaes e de outros objectos mormente ethnographicos colligidos na Provincia de Angola. Lisboa, Imprensa Nacional.

WELWITSCH Friederich, 1867, «Informação do Doutor Frederico Welwitsch» on September 10, 1856, in Annaes do Conselho Ultramarino (parte não official), Fevereiro de 1854 a Dezembro de 1858. Lisboa, Imprensa Nacional, pp. 293-294.

WELWITSCH Friederich, 1962, «Welwitsch on August 20, 1861», in Cultura do Algodão: Notícia sobre esta cultura e modo de trazer o seu producto ao commercio. Lisboa, Imprensa Nacional, pp. 31-39.

WHEELER Douglas, 1996, «Angolan woman of means: D. Ana Joaquina dos Santos e Silva, midnineteenth century Luso-Africa merchant-capitalist of Luanda», Santa Barbara Portuguese Studies, vol. III, pp. 284-297. 


\section{NOTAS}

1. A crença segundo a qual a agricultura orientada para o mercado constituiria o fundamento para novas relações coloniais com a África, serviu de base para políticas adoptadas por outras nações europeias. Ver Hopkins (2009: 784); Reynolds (1974: 65).

2. Castelo Branco afirmou que tinha ordenado a compra de um engenho no Brasil e que outro engenho tinha sido estabelecido perto do rio Bengo em 1826. Ver Almanak Statistico da Província d'Angola e suas dependências para o ano de 1852 (1851: 11).

3. «Ofício do Governador de Angola» em 8 de Abril de 1836, AHNA, cód. 13, fls. 5-10v.

4. «Primeira comunicação da Companhia de Agricultura e Indústria de Angola e Benguela» em 21 de Março de 1836, AHU, segunda secção de Angola, pasta 2.

5. «Regulamentos da Companhia de Agricultura e Indústria de Angola e Benguela» em 21 de março 1836, AHU, segunda secção de Angola, pasta 2.

6. «Relatório do Governador de Angola» em 22 de Fevereiro de 1850, AHU, segunda secção de Angola, pasta 16.

7. «Ofício do Governador de Angola» em 23 de Março de 1839, AHNA, cód. 14. Para esforços similares em outras regiões africanas, ver Ray Kea (1993: 138).

8. «Relatório de António Manoel de Noronha» em 6 de Agosto de 1838, AHU, segunda secção de Angola.

9. Almanak Statistico da Província d'Angola... (1851: XXI).

10. Portaria» em 17 de abril de 1839, AHNA, cód. 1081.

11. «Ofício do Governador de Angola» em 24 de Maio de 1839, AHNA, cód. 14, fls. 27.

12. «Portaria Circular do Conselho de Governo» em 3 de Abril de 1839, AHNA, cód. 101, fls. 90v.-91.

13. «Relatório da Província entre 17 de Agosto de 1848 a 31 de Dezembro de 1849» em 20 de Janeiro de 1850, AHNA, cód. 19, fls. 31v.-53v.

14. «Ofício do Governador de Angola» em 20 de Abril de 1839, AHNA, cód. 14, fls. 11v.-12v.

15. «Ofício do Governador de Angola» em 12 de Dezembro de 1840, AHU, segunda secção de Angola, pasta 3 C; «Ofício do Governador de Angola» em 28 de Outubro de 1839, AHNA, cód. 14, fls. $65 \mathrm{v} .-66$.

16. «Ofício do Secretário Geral da Provincia de Angola» em 26 de Agosto de 1846, AHNA, cód. 325, fls. $29 \mathrm{v} .-30$

17. «Ofício do Alferes Ajudante de ordens J. B. de Sampaio» em 31 de Agosto de 1846, AHNA, cód. 1082. Em 1847, numa das suas viagens a Luanda para comercializar uma carga de milho, Aquitamba informaria à administração que tinha começado a cultivar café, tabaco e algodão. Ver «Ofício do Secretário Geral da Província de Angola» em 1 de Julho de 1847, AHNA, cód. 325, fls. $171-171 \mathrm{v}$

18. «Ofício do Governador de Angola» em 6 de Junho de 1840, AHNA, cód. 15, fl. 11.

19. Report on the Slave Trade by Edmond Gabriel and George Jackson em 18 de Fevereiro de 1847, FO $84,671,1847$, fls. 99-11.

20. «Ofício do Governador de Angola» em 14 de Dezembro de 1830, AHU, cx. 167, doc. 46.

21. «Diário da viagem feita pelo Governador Geral de Angola Manoel Eleutério Malheiros ao Distrito de Icolo e Bengo» em 17 de janeiro de 1841, AHU, segunda secção de Angola, pasta 4 B.

22. Almanak Statistico da Província d'Angola... (1851: 11).

23. Report on the Slave Trade by Gabriel and Jackson em 18 de Fevereiro de 1847, PRO, FO 84, 671, 1847, fls. 99-11.

24. «Relatório da visita feita aos distritos do Bengo, Icolo, Barra do Dande e Alto Dande, por Adrião Acácio da Silveira Pinto» em 28 de Agosto de 1850, AHU, papéis de Sá da Bandeira, maço 823; Douglas Wheeler (1996: 286).

25. Almanak Statistico da Província d'Angola... (1851: 11). 
26. «Instruções para o Capitão do Batalhão de Infantaria de Linha de Luanda Joaquim Olavo Gamboa» em 28 de Maio de 1850, AHNA, cód. 1178, fls. 104v.-106v.

27. «Ofício do Governador de Angola» em 8 de Agosto de 1851, AHNA, cód. 20, fls. 62v.-63.

28. «Comentários de Francisco José da Costa Silva sobre a Memória sobre as imediatas providências que precisa Benguela e Angola» em 1856, AHU, segunda secção de Angola, pasta 22 A.

29. «Portaria ao Governador de Angola» em 6 de Fevereiro de 1845, Annaes Maritimos e Coloniaes, n. ${ }^{\circ}$ 3, Fevereiro de 1845 , p. 36.

30. Posteriormente, os administradores dos contratos de tabaco prometeram comprar todo o tabaco enviado para Lisboa. Ver Francisco de Salles Ferreira (1877: 9, 16).

31. Almanak Statistico da Província d'Angola... (1851: 11).

32. Annaes Maritimos e Coloniaes (n.․ 8, Julho de 1845: 126).

33. «Extrato de uma carta do Sr. Physico-Mor da Província de Angola Jacques Nicolau de Sales sobre o Estado da Colonia de Mossamedes» em 1855, Annaes do Conselho Ultramarino (1867: 252).

34. Dispatch by Gabriel on April 3, 1858, FO 84, 1043, 1858, fls. 222-231.

35. Dispatch by Gabriel on April 3, 1858, FO 84, 1043, 1858, fls. 222-231.

36. Report on the slave trade by Gabriel em 25 de Fevereiro de 1860, FO 84, 1104, 1860, fls. 234-260v.

37. «Ofício do Governador de Angola» em 30 de Setembro de 1848, AHNA, cód. 18, fls. 23-24.

38. «Ofício do Governador de Angola» em 10 de Outubro de 1827, AHU, Angola, cx. 156.

39. «Carta do Governador de Angola» em 6 de Março de 1829, AHNA, cód. 97, fls. 4.

40. «Ofício de António Manoel de Noronha» em 17 de Abril de 1827, AHNA, cód. 7183, fl. 58v.; «Ofício de António Manoel de Noronha» em 5 de Maio de 1827, AHU, segunda secção de Angola, pasta 4; «Ofício de António Manoel de Noronha» em 3 de Julho de 1827, AHU, segunda secção de Angola, pasta 4.

41. «Acta da Sessão da Junta da Fazenda» em 16 de Abril de 1841, AHU, segunda secção de Angola, pasta $4 \mathrm{~B}$

42. «Relatório do Governador de Angola» em 22 de Fevereiro de 1850, AHU, segunda secção de Angola, pasta 16. Para um relatório anterior sobre o café silvestre em Encoje, ver «Ofício do Secretário da Província de Angola» em 26 de Novembro de 1847, AHNA, cód. 325, fls. 248v.-249.

43. «Ofício do Sargento Cabo do Cazengo» em 15 de Abril de 1832, AHU, Angola, cx. 173, doc. 106.

44. «Instrução para o Governador de Angola» em 4 de Novembro de 1838, AHNA, cód. 259, fls. 225-231v.

45. Almanak Statistico da Província d'Angola... (1851: 11); «Decreto real» em 20 de Julho de 1845, Annaes Maritimos e Coloniaes (n.․ 8, Julho de 1845: 127).

46. Dizia-se então que esta logo alcançaria 1000 sacas. Ver «Ofício do Governador de Angola» em 28 de Janeiro de 1840, AHU, segunda secção de Angola, pasta 3 A.

47. «Ofício de João Guilherme Pereira Barboza» em 25 de Fevereiro de 1847, in Luiz António de Figueiredo (1864: 50); «Ofício do Governador de Angola» em 14 de Novembro de 1846, AHNA, cód. 16 , fls. $239-239 \mathrm{v}$.

48. A estimativa para o total da produção de café é originada de «Ofício de João Guilherme Pereira Barboza» em 17 de October de 1845, in Luiz António de Figueiredo (1864: 50).

49. «Relatório do Governador de Angola» em 22 Fevereiro de 1850, AHU, segunda secção de Angola, pasta 16; Caldeira (1853: 212).

50. Almanak Statistico da Província d'Angola... (1851: 12).

51. «Ofício de Carlos Possolo de Sousa» em 29 de Outubro de 1852, AHNA, cód. 110.

52. «Ofício do Governo Geral de Angola» em 10 de Fevereiro de 1846, in Figueiredo (1864: 65).

53. Ofício do Governo Geral de Angola» em 10 de Fevereiro de 1846, in Figueiredo (1864: 65); «Relatório do Ministério da Marinha e Ultramar» de 2 de Março de 1846, Annaes Maritimos e Coloniaes (n.․ 8, julho de 1845: 157). Ver também Francisco Valdez (1864: 95). Não foi a primeira 
vez que camelos foram importados para Angola uma vez que esses animais tinham sido importados em 1839. Ver Lima (1864: 18).

54. «Ofício de João Guilherme Pereira Barboza» em 19 de Julho de 1846, in Figueiredo (1864: 50).

55. Carta de Welwitsch em 15 de Março de 1858, FO 84, 1043, 1858, fls. 236-245.

56. «Ofício do Secretário Geral da Província de Angola» em 8 de Dezembro de 1846, AHNA, cód. 325 , fls. $87 \mathrm{v}-88$.

57. «Ofício do Chefe do Distrito do Golungo Alto» em 3 de Janeiro de 1840, AHU, segunda secção de Angola, pasta 3 A; «Ofício do Governador de Angola» 3 de Março de 1840, AHU, segunda secção de Angola, pasta $3 \mathrm{C}$.

58. «Diário de uma viagem ao sertão» em 25 de Julho de 1840, AHNA, cód. 15, fls. 28-32.

59. Para a Costa de Ouro, ver Kea (1995: 137); para o Benin, ver Manning (1982: 13); para os Camarões, ver Ralph Austen e Jonathan Derrick (1999: 87).

60. «Representação dos habitantes de Benguela» em 30 de Setembro de 1839, AHU, segunda secção de Angola, pasta 5.

61. Report on the Slave Trade by Edmond Gabriel e George Jackson em 18 de Fevereiro de 1847, FO 84, 671, 1847, fls. 99-111. Ver Paul Lovejoy e David Richardson (1995: 98-119).

62. Dispatch by Gabriel em 3 de Abril de 1858, FO 84, 1043, 1858, fls. 222-231.

63. «Memória sobre a Cultura do Algodão» em 28 de Fevereiro de 1852, AHU, segunda secção de Angola, pasta 18 A. Para a conexão entre agricultura e o crescimento do número de escravos no antigo Reino de Calabar, ver A. J. H. Latham (1973: 91).

64. Na altura, o número de escravos em Mossâmedes foi percebido como «considerável» por um viajante britânico. Ver William Meseum (1867: 253-257).

65. «Decreto de 14 de Dezembro de 1854», in A abolição do tráfico e da escravatura em Angola: Documentos (1997: 35-38).

66. «Ofício do Secretário do Governo» em 20 de Setembro de 1856, AHNA, cód. 857, fls. 13-13v.

\section{RESUMOS}

Este artigo trata da renovação dos laços coloniais entre Portugal e Angola na primeira metade do século XIX, enfocando sobretudo as tentativas de estabelecer uma agricultura de larga escala, plantation, na colónia portuguesa. $O$ texto documenta as várias propostas de agricultura comercial que circularam em Angola e Portugal, assim como as diferentes culturas agrícolas que os portugueses priorizaram: café, algodão, açúcar e tabaco. 0 texto demonstra que a administração colonial actuou de forma concertada e com os resultados desiguais na execução do objectivo de «refundar» a economia de Angola depois do tráfico atlântico de escravos.

This article deals with the renewal of colonial ties between Portugal and Angola in the first half of the nineteenth century. Mainly focuses on the attempts to establish a large-scale agriculture in the Portuguese colony. The text documents the various projects for commercial agriculture circulated in Angola and Portugal, as well as the different crops that Portuguese prioritized: coffee, cotton, sugar and tobacco. The text shows that, after the Atlantic slave trade, the colonial administration acted in concert and with different results in implementing the objective of «refounding» the economy of Angola. 


\section{ÍNDICE}

Palavras-chave: escravatura, abolicionismo, produção agrícola, culturas agrícolas, agricultura de larga escala, laços coloniais, Portugal, Angola

Keywords: slavery, abolitionism, agricultural production, agricultural crops, large-scale farming, colonial ties, Portugal, Angola

\section{AUTOR}

\section{ROQUINALDO FERREIRA}

roquinaldo_ferreira@brown.edu

Vasco da Gama associate professor in History/Portuguese and Brasilian Studies na University of Brown, nos Estados Unidos da América. É doutor em História de África pela Universidade da Califórnia, Los Angeles, nos EUA. A sua tese de doutoramento, defendida em 2003, intitula-se Transforming Atlantic slaving: Trade, warfare and territorial control in Angola, 1650-1800 e foi preparada sob orientação do Prof. Dr. Edward Alpers.

Nascido na cidade de Salvador, Bahia, República Federativa do Brasil, em 28 de Novembro de 1967, é licenciado em História (1992) e mestre em História Social (1996) pela Universidade Federal do Rio de Janeiro (UFRJ). No período de 1993 a 1997, foi pesquisador assistente no Centro de Estudos Afro-Asiáticos da Universidade Cândido Mendes no Rio de Janeiro; entre 2000 e 2002, foi pesquisador assistente na Hull University, na Inglaterra; em 2005, foi professor visitante na Universidade Federal Fluminense (UFF), em Niterói, RJ, Brasil; de 2005 a 2010, foi assistent professor of African and African American History, na University of Virginia (EUA) e a partir de 2011, foi associate professor of African and African American History nessa mesma instituição universitária. Actuamente, é Vasco da Gama associate professor in History/ Portuguese and Brazilian Studies na University of Brown (EUA). É membro do Conselho Científico da Mulemba Revista Angolana de Ciências Sociais. Além de artigos em revistas especializadas e estudos em capítulos de livros, é autor das obras seguintes: Cross-cultural exchange in the Atlantic World. Angola and Brazil during the Era of the Slave Trade (New York, Cambridge University Press, 2012) e Dos Sertões ao Atlântico. Tráfico ilegal de escravos e comércio lícito em Angola, 1830-1860 (Luanda, Kilombelombe, 2012). Tem em preparação a obra Pathways to colonialism: abolitionism, territorial sovereignty, and unfree labor in Angola (ca. 1830-ca. 1860s). 